\title{
A COMPARATIVE STUDY OF THE EFFICACY OF POWERED (MICRO DEBRIDER) INSTRUMENTS AND STANDARD TECHNIQUES IN ENDOSCOPIC SINUS SURGERY FOR SINONASAL POLYPOSIS
}

\author{
Tarun Sood ${ }^{1}$, Jeevan R. Galagali², Sanajeet K. Singh ${ }^{3}$, Suresh Mokamati', Nikhil Kumar ${ }^{5}$ \\ ${ }^{1}$ Consultant, Department of ENT, Base Hospital, Bagdogra, West Bengal. \\ ${ }^{2}$ Senior Advisor \& HOD, Department of ENT, CH (SC), Pune, India. \\ 3Professor, Department of ENT, AFMC, Pune, India. \\ ${ }^{4}$ Resident, Department of ENT, AFMC, Pune, India. \\ ${ }^{5}$ Resident, Department of ENT, AFMC, Pune, India.
}

\section{ABSTRACT}

Endoscopic Sinus Surgery (ESS) is the surgical procedure of choice for Sinonasal Polyposis (SP). Bleeding during Endoscopic Sinus Surgery can interrupt the flow of surgery. The standard instruments grab and tear diseased tissues along with normal tissues causing increased intraoperative bleeding leading to decreased visibility and thus less precise surgery. The advent of powere d instruments (Microdebrider), allowed easy dissection with minimal bleeding giving surgeon a clear uninterrupted surgical field. With acknowledgement of the fact that use of microdebrider leads to comfortable dissection and decreased rate of intra-operative complications. We endeavoured to find whether there are any long term benefits of use of microdebrider.

\section{MATERIALS AND METHODS}

Our patient population comprised 50 patients who underwent Endoscopic Sinus Surgery for SP from Aug 2011 to Jun 2012 . All surgeries were performed with either the microdebrider (Group 1) or Standard (Group 2) instruments. We evaluated them preoperatively for degree of nasal obstruction (NOSE Score), quality of life (SF-12), nasal epithelial function (Saccharin test) and olfactory status. The same were evaluated 6 months post-op and comparisons were made between two groups.

\section{RESULTS}

After statistical analysis we found that there was no statistically significant difference between the two groups preoperatively and post-operatively in terms of above mentioned parameters. However, both groups showed significant improvement in parameters when assessed individually.

\section{CONCLUSION}

We concluded that use of microdebrider does not offer any long-term benefits over standard instruments in Endoscopic Sinus Surgery for SP.

\section{KEYWORDS}

Endoscopic Sinus Surgery, Sinonasal Polyposis, Microdebrider.

HOW TO CITE THIS ARTICLE: Sood T, Galagali JR, Singh SK, et al. A comparative study of the efficacy of powered (micro debrider) instruments and standard techniques in endoscopic sinus surgery for sinonasal polyposis. J. Evolution Med. Dent. Sci. 2016;5(43): 2710-2713, DOI: $10.14260 /$ jemds/2016/633

\section{INTRODUCTION}

Nasal polyps are round, soft, semi-translucent, pale or yellow glistening swellings that originate from any part of the nasal mucosa or paranasal sinuses. They are the most common mass lesions encountered in the nose. Polyp development has been linked to chronic inflammation, allergy, autonomic nervous system dysfunction and genetic predisposition. Polyps are usually bilateral and are found in the maxillary, ethmoid and sphenoid regions, although they can originate from any part of the nasal mucosa or paranasal sinuses.(1)

The introduction of high-quality nasal endoscopes has markedly improved intraoperative visualization by the intranasal route. Trauma to normal structures and hence postoperative morbidity is minimized and precise meticulous

Financial or Other, Competing Interest: None.

Submission 15-04-2016, Peer Review 09-05-2016,

Acceptance 16-05-2016, Published 30-05-2016.

Corresponding Author:

Dr. Suresh Mokamati,

Department of ENT,

AFMC, Pune-411040,

India.

E-mail: drsuresh.mokamati@gmail.com

DOI: $10.14260 /$ jemds $/ 2016 / 633$ surgery to restore physiologic routes of drainage and reestablish ventilation is possible.(2) This is in stark contrast to non-endoscopic intranasal procedures, where there is increased blood loss and damage to the normal structures causing significant scarring and poor functional results. Since the Functional Endoscopic Sinus Surgery (FESS) techniques have been standardized, external approaches to the sinuses are rarely performed currently. FESS techniques have proven to be far superior to other conventional modalities of treatment followed earlier.(1)

With currently available FESS instruments, surgeons often find that they cannot do the precise and delicate surgery demanded by the functional approach. Consequently, the goals of meticulous cutting, a near bloodless field, unimpaired vision and continuous removal of resected tissue remains elusive. The instruments used so far are "grabbing" tools that grab and tear normal tissues along with the diseased tissues. This grab and tear approach predisposes to increased bleeding, which is the arch enemy of the surgeon, because it leads to decreased visibility, the cornerstone of complications. The lack of continuous suction at the operative site is a technical limitation that compounds the stress of the surgeon and increases inherent risk for the patient.(3) 
In 1994, Setliff and Parsons introduced microdebrider (shaver) to endoscopic sinus surgery.(4) The microdebrider is a powered rotary shaving device with continuous suction used during FESS. It is made up of a cannula connected to a hand piece, which in turn is connected to a motor with foot control and a suction device. The cannula is made up of two parts, an outer blunt tip with a lateral port and an oscillating inner cannula with a similar lateral port. Lateral port of the inner cannula has serrated blade which cuts and extracts soft tissue, as it is suctioned through the side port of the cannula. The blunt tip of the outer cannula protects vital structures within the sinuses and only the soft tissues that are sucked into the lateral port is cut.

Nasal polypectomies using the microdebrider are performed in a more precise manner with very little blood loss. Because the blood loss is minimal and the operative field's clear removal of the disease is complete and the recurrence rate is low when compared to conventional polypectomies.(5), it is increasingly replacing conventional instruments in FESS the world over.

The description of a new technique raises the question whether it provides any significant advantage in methodology over the conventional procedure. Previous studies about this subject focused on less tissue damage, less bleeding and complications.(6)(7) The focus of this study will be to evaluate difference in long-term outcomes.

\section{MATERIAL AND METHODS}

This study was carried out in a tertiary care centre on 50 patients over a period of 2 years. All cases of SP between the age of 18-60 years planned for endoscopic sinus surgery after at least 12 wks. of medical management in the form of intranasal steroids were included in the study. All patients unwilling to participate or with other associated nasal pathology like deviated nasal septum or having undergone Sinus Surgery previously or with other systemic illness were excluded from the study.

All cases of sinonasal polyposis who presented to our tertiary care hospital were treated with twelve weeks of topical steroid nasal spray in the form of Fluticasone nasal spray 2 puff once a day in both nostrils and tablet cetirizine hydrochloride $10 \mathrm{mg}$ once a day.

Symptoms resistant after medical therapy were taken up endoscopic sinus surgery. Written informed consent was taken from all the patients. The subjects were selected by simple random sampling for surgery by microdebrider (Treatment) and standard cold instruments (Control). Pre- and postoperative data was collected without being told to which group the patient belongs.

50 consecutive patients undergoing endoscopic sinus surgery for sinonasal polyposis formed the study population, of these 26 were operated by using microdebrider (M) (Group 1) and 24 by standard technique (S) (Group 2) using cutting instruments as described by Kennedy and Messerklinger. In the microdebrider group, the procedure was mostly completed using microdebrider with minimal use Blakesley forceps. In the group operated using standard instruments, microdebrider was not used at all. In both surgical groups only sinuses which were diseased were attended to. This decision was taken based upon CT findings, which was taken 1 week prior to surgery.

\section{DATA COLLECTION}

Preoperative data collection was done within one week prior to surgery before committing to any particular technique of surgery. Same was also collected 6 months post-operatively. Variables and data collection was done by a person who was not informed about the group to which the patient belongs.

\section{The Parameters used were as under:}

\section{a. Nasal Obstruction (NO)}

It was measured using NOSE (Nasal Obstruction Symptom Evaluation) Score approved by American Academy of Otolaryngologists - Head and Neck Surgery (AAO-HNS) Foundation 2002.

\section{b. Nasal Epithelial Function (NEF)}

It was assessed using saccharin test and nasal transit time was measured. Saccharin pellet was placed in the inferior meatus and time taken for perception of the sweetness was noted and taken as a measure of nasal transit time.

\section{c. Hyposmia (Hyp)}

The degree of sense of smell was measured by using Visual Analogue Score (VAS).

\section{d. Quality of Life (QOL)}

It was measured using the SF-12 questionnaire. The Questionnaire was filled and the score were calculated by the free website, http://www.sf-36.org/demos/sf12.html.

Immediate post-operative data collection was done for maximum pain suffered by the patients within $12 \mathrm{hrs}$. of surgery using VAS before giving analgesia for post-op pain relief and for bleeding. The no. of nasal packs required to change, so as to achieve haemostasis were noted. All patients were packed using nasal pack manufactured by same company and were removed after 48 hours if no internal bleeding occurred.

\section{RESULTS}

Out of a total of 50 patients, 12 were female with mean age of 35.92 yrs. and 38 were male with mean age of 37.63 yrs. Overall, mean age was 37.22 yrs. (Table 1). There was no difference in sex distribution with respect to age using two sample t-test $(\mathrm{T}=-0.41, \mathrm{P}=0.682) ; 26$ patients were operated by using microdebrider and 24 by using standard technique.

\section{Comparison between Techniques}

After comparison between the two groups with respect to percentage change before and after the surgical procedure for different variables under study, we found that the difference in mean percentage change between two groups was statistically not significant for any variables, namely NO $\mathrm{P}=0.842$ (Graph 1), Hyp P = 0.286 (Graph 2), NEF P = 0.487 (Graph 3), QOL P $=0.191$ (Graph 4), pain $P=0.821$. For these two sample t-test has been used. However, with respect to bleeding only 2 out of 50 patients required change of nasal packs and that too only once in the post-operative period. One patient amongst these belonged to group operated by standard technique and one by microdebrider. Therefore, indicating that both techniques no difference in immediate post-op period.

Comparison Pre- and Post-Op Separately for Two Groups However, after analysing these two groups individually, we found that both groups showed highly significant 
improvement in variables for Group 1 for NO (S) $\mathrm{P}=0.0001$, Hyp (S) P=0.0001, QOL (S) P = 0.0001, NEF (S) P=0.0001 and in Group 2 for NO (M) P=0.0001, Hyp (M) P=0.0001, QOL (M) $\mathrm{P}=0.0001, \operatorname{NEF}(\mathrm{M}) \mathrm{P}=0.0001$.

\begin{tabular}{|c|c|c|c|c|}
\hline Variable & Sex & N & Mean Age & SD \\
\hline \multirow{2}{*}{ Age } & $\mathrm{F}$ & 12 & 35.92 & 12.64 \\
\cline { 2 - 5 } & $\mathrm{M}$ & 38 & 37.63 & 12.53 \\
\hline \multicolumn{5}{|c|}{ Table 1 } \\
\hline & Overall & 50 & 37.22 & 12.45 \\
\hline
\end{tabular}

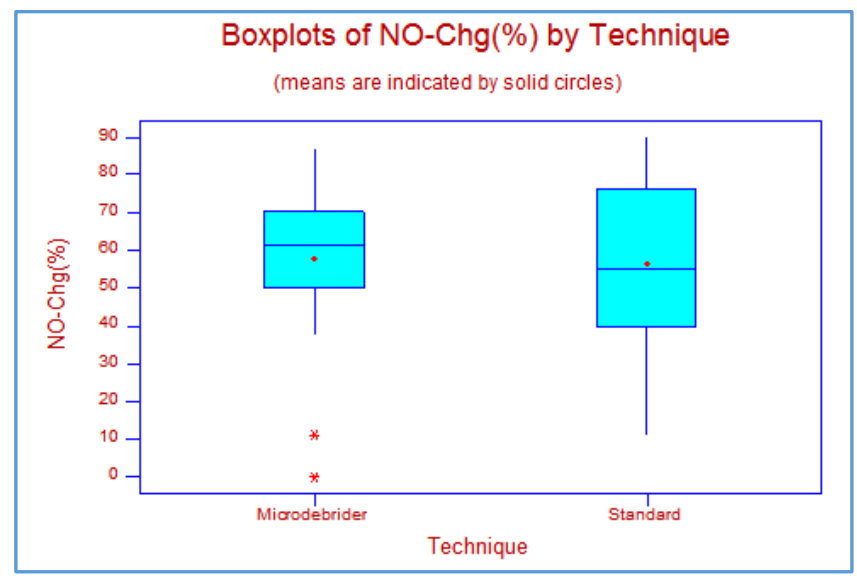

Graph 1

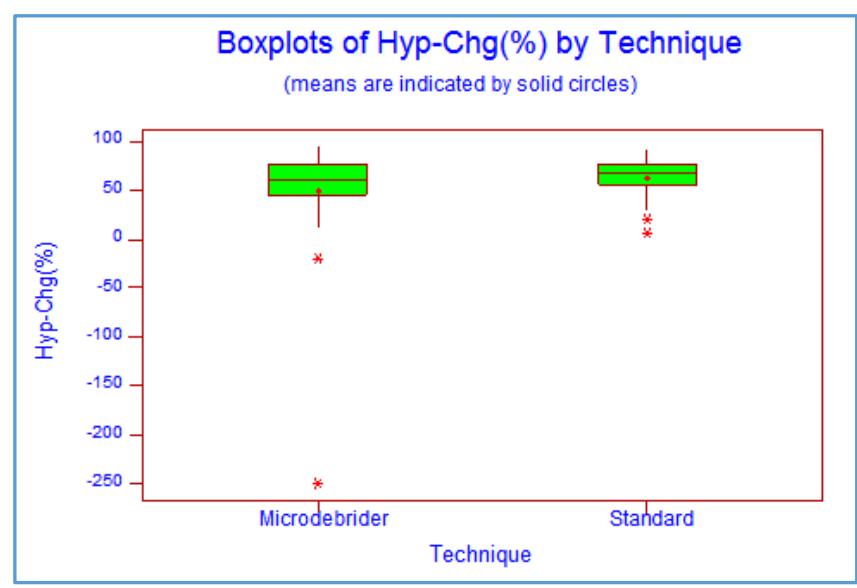

Graph 2

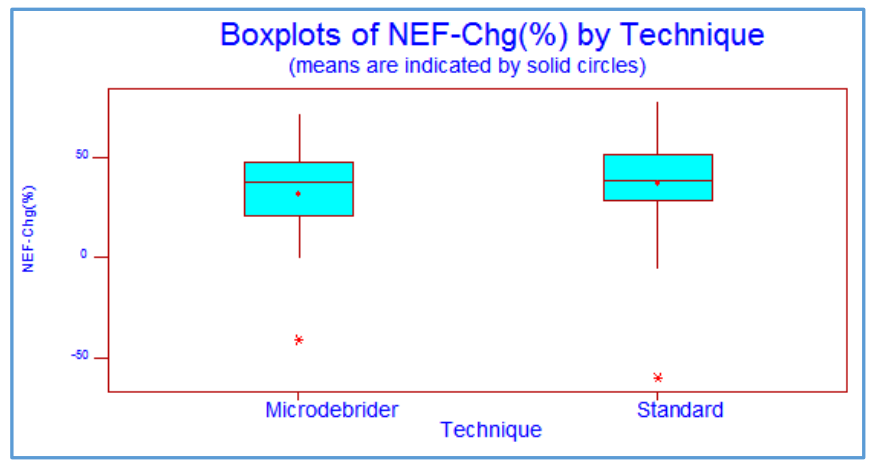

Graph 3

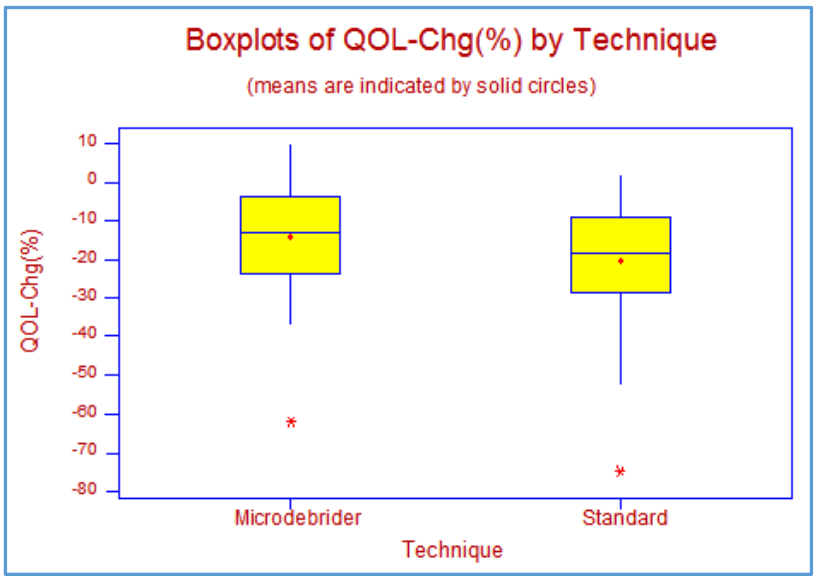

Graph 4

\section{DISCUSSION}

FESS claims advantage over conventional surgery permitting a better view of the surgical field. It allows precise and through clearance of pathology and is associated with fewer complication and lower recurrence rates.(8) Evidence of effectiveness of FESS comes from a series of RCT's.

With the constant evolving surgical techniques of FESS, newer and more sophisticated instruments are constantly being introduced into this field. With the introduction of powered instruments like microdebrider, particularly in patients with polyposis surgical tools are undergoing a change in generation. It is a well-known fact and is being recognised by most emerging sinus surgeons that microdebrider provides bloodless surgical field, decreases intra-operative time and is associated with lesser crusting, synechiae and ostial reocclusion.(9) However, evidence of long-term benefits by using microdebrider is lacking or is not of sufficient stature. In our study, we attempt to contribute to same.

Kursat Ceylon et al carried out a randomised single blinded clinical study on 97 patients in 1997 to compare the outcomes of two groups of nasal polyposis treated surgically with traditional instruments and powered instruments. There was no statistically significant change in post-op outcomes of two groups.(5)

Krause JH et al also carried out a study on two groups. A group of 250 patients undergoing surgery with the microdebrider was compared with the group of 225 patients undergoing surgery with traditional technique. The use of microdebrider demarcated faster healing, less crusting, less synechiae formation and less ostial reocclusion, therefore claiming fewer complications faster healing by use of microdebrider. ${ }^{(9)}$

Bernstein JM et al carried out a study in 1998 on 40 patients operated by microdebrider. On a five month followup, they demarcated rapid mucosal healing, minimal crust formation and a low incidence of synechiae formation. With the constant evolving surgical techniques of FESS, newer and more sophisticated instruments are constantly being introduced into this field.

With conflicting results in literature behind us, we carried out this study. It is clear from our results that the use of microdebrider does not offer any post-operative advantage vis-a-vis standard cold instruments which have stood the test of time. However, it must be kept in mind that the basic principles of functional endoscopic sinus surgery must be kept 
in mind, no matter which technique is used. However, we have not assessed the advantages of these techniques intraoperatively, where literature supports that the microdebrider is beneficial as brought about in review of literature. It therefore needs to be questioned that whether the use of microdebrider is solely for the ease of surgery and decreasing incidence of intra-operative complications is justified whereby increasing intra-operative cost and giving no advantage to patients as far as long-term benefits or disease progression or regression is concerned.

Microdebrider, as known today, are in widespread use. However, the degree of work carried or extent of sinus surgery carried out by microdebrider varies from one surgeon to other and also between two surgeries done by same surgeon. Therefore, measuring results has its own difficulties when carrying out such studies. To carry out more such studies standardization of surgical steps in detail is required and must be followed diligently.

It must be remembered that without medical management any surgery that is done in sinonasal polyposis is of no value and therefore medical management should be first line of management in sinonasal polyposis.

\section{REFERENCES}

1. Dalziel K, Stein K, Round A, et al. Systematic review of endoscopic sinus surgery for nasal polyps. Health Technol Assess 2003;7(17):1-159.

2. Michael Gleason. Scott-browns otolaryngology, head and neck surgery. Edward Arnold publishers 2008; $7^{\text {th }}$ edn:p 1482.
3. Vauterin T, Vander Poorten V, Jorissen M. Long term effects of cutting forceps in endoscopic sinus surgery. Rhinology 2006;44(2):123-7.

4. Setliff RC. The hummer: a remedy for apprehension in functional endoscopic sinus surgery. Otolaryngol Clin North Am 1996;29(1):95-104.

5. Kürpat Ceylan, Ünal Bayiz, Zeynep Kizilkaya, et al. Impact of microdebrider in surgical treatment of nasal polyposis in terms of health related quality of life and objective findings: a comparative randomized single blinded clinical study. Ministry of health Ankara training and research hospital, E.N.T. Department, Ankara, Turkey published in KBB-Forum, Istanbul 2007;6(2).

6. Bernstein JM, Lebowitz RA, Jacobs JB. Initial report on postoperative healing after endoscopic sinus surgery with the microdebrider. Otolaryngol Head Neck Surg 1998;118(6):800-3.

7. Sauer M, Lemmens W, Vauterin T, et al. Comparing the microdebrider and standard instruments in endoscopic sinus surgery: a double-blind randomised study. BENT 2007;3(1):1-7.

8. Slack R, Bates G. Functional endoscopic sinus surgery. Am Fam Phys 1998;58(3):707-18.

9. Krause JH, Christmas DA. Powered instrumentation in functional endoscopic sinus surgery. II: a comparative study. Ear Nose Throat J 1996;75(1):42-4. 